Marquette University

e-Publications@Marquette

Biomedical Sciences Faculty Research and

Publications

Biomedical Sciences, Department of

5-10-2018

Organic Cation Transporter 3: A Cellular Mechanism Underlying Rapid, Non-Genomic Glucocorticoid Regulation of Monoaminergic Neurotransmission, Physiology, and Behavior

Paul J. Gasser

Marquette University, paul.gasser@marquette.edu

Christopher A. Lowry

University of Colorado - Boulder

Accepted version. Hormones and Behavior, (In Press, Corrected Proof), Available online May 10, 2018. DOI. (C) 2018 Elsevier B.V. Used with permission. 


\section{Marquette University}

\section{e-Publications@Marquette}

\section{Biomedical Sciences Faculty Research and Publications/College of Health Sciences}

This paper is NOT THE PUBLISHED VERSION; but the author's final, peer-reviewed manuscript. The published version may be accessed by following the link in the citation below.

Hormones and Behavior, (in press, corrected proof) Available online May 20, 2018). DOI. This article is (C) Elsevier and permission has been granted for this version to appear in e-Publications@Marquette. Elsevier does not grant permission for this article to be further copied/distributed or hosted elsewhere without the express permission from Elsevier.

\section{Contents}

Abstract .2

Graphical abstract 2

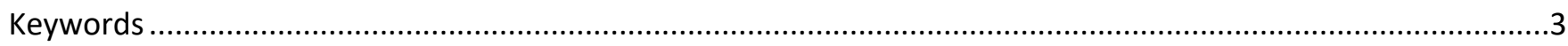

1. Stress physiology: the sympathetic nervous system and hypothalamic-pituitary-adrenal axis ..........................3

2. Historical perspectives for interactions between glucocorticoids and monoaminergic uptake/clearance...........3

3. Rapid nongenomic effects of corticosterone in an amphibian model .........................................................

4. Co-regulation of DA and 5-HT in the $\mathrm{DMH}$; a clue to novel regulatory mechanisms? ..................................4

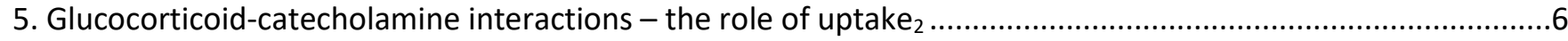

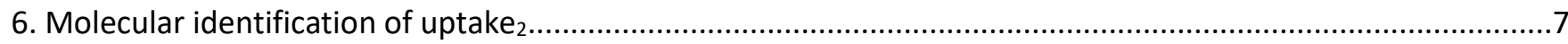

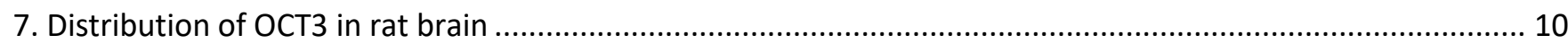

8. Interactions between stress, glucocorticoids, and norepinephrine/epinephrine: the role of OCT3 ................. 11

9. Interactions between stress, glucocorticoids, and dopamine: the role of OCT3 …...................................... 12

10. Interactions between stress, glucocorticoids, and serotonin: the role of OCT3

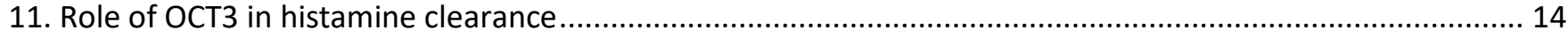

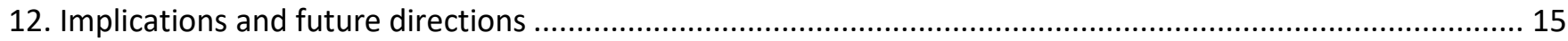

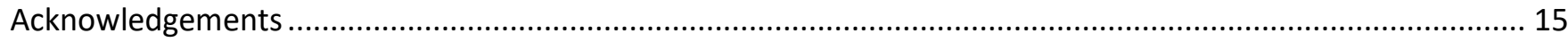

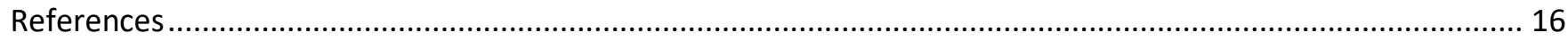




\title{
Organic Cation Transporter 3: A Cellular Mechanism Underlying Rapid, Non-Genomic Glucocorticoid Regulation of Monoaminergic Neurotransmission, Physiology, and Behavior
}

\author{
Paul J. Gasser \\ Department of Biomedical Sciences, Marquette University, Milwaukee, WI
}

Christopher A. Lowry

Department of Integrative Physiology and Center for Neuroscience, University of Colorado Boulder, Boulder, CO

\section{Abstract}

Corticosteroid hormones act at intracellular glucocorticoid receptors (GR) and mineralocorticoid receptors (MR) to alter gene expression, leading to diverse physiological and behavioral responses. In addition to these classical genomic effects, corticosteroid hormones also exert rapid actions on physiology and behavior through a variety of non-genomic mechanisms, some of which involve GR or $M R$, and others of which are independent of these receptors. One such GR-independent mechanism involves corticosteroid-induced inhibition of monoamine transport mediated by "uptake" transporters, including organic cation transporter 3 (ОСТ3), a low-affinity, high-capacity transporter for norepinephrine, epinephrine, dopamine, serotonin and histamine. Corticosterone directly and acutely inhibits OCT3-mediated transport. This review describes the studies that initially characterized

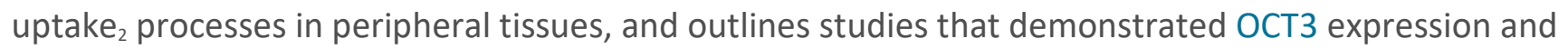
corticosterone-sensitive monoamine transport in the brain. Evidence is presented supporting the hypothesis that corticosterone can exert rapid, GR-independent actions on neuronal physiology and behavior by inhibiting OCT3-mediated monoamine clearance. Implications of this mechanism for glucocorticoid-monoamine interactions in the context-dependent regulation of behavior are discussed.

Graphical abstract

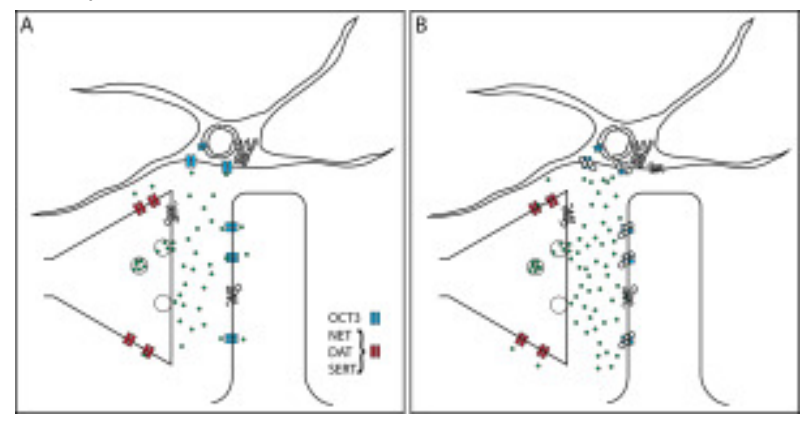




\section{Keywords}

Corticosterone, Dopamine, Epinephrine, Extraneuronal monoamine transporter, Histamine, Norepinephrine, OCT3, Organic cation transporter 3, Serotonin, slc22a3, Solute carrier family 22 (organic cation transporter), member 3

\section{Stress physiology: the sympathetic nervous system and hypothalamic- pituitary-adrenal axis}

The central nervous system coordinates the physiological stress response through activation of two distinct systems, the sympathetic division of the autonomic nervous system and the hypothalamicpituitary-adrenal (HPA) axis. The sympathetic nervous system is responsible for the adaptive fight-orflight response that enables a rapid and strategic deployment of resources to confront immediate real or perceived threats. Postganglionic sympathetic fiberspredominantly signal via the release of catecholamines (norepinephrine and epinephrine) at synapses in target organs. In addition, preganglionic acetylcholinergic fibers innervating chromaffin cells in the adrenal medulla act at neuronal-type nicotinic acetylcholine receptors(nAChRs) receptors (Sala et al., 2008) to induce the release of predominantly epinephrine, which enters systemic circulation and acts in a hormonal fashion to influence target tissues throughout the body. The latter system is referred to as the sympatho-adrenomedullary-axis (SAM) (Turner et al., 2012). Thus, the sympathetic nervous system response includes a very rapid release of catecholamines at specific target tissues via postganglionic fibers, and a slightly delayed hormonal action of catecholamines, predominantly epinephrine, acting through hormonal mechanisms.

Alongside these relatively rapid physiologic responses to real or perceived threats is an activation of the HPA axis. The HPA axis hormonal cascade involves activation of corticotropin-releasing hormone(CRH)-producing neurons in the parvocellular region of the paraventricular nucleus of the hypothalamus (PVN), which themselves are under control of a hierarchical system coordinating physiologic and behavioral responses to stressors (Herman and Cullinan, 1997; Herman et al., 2002a, Herman et al., 2002b; Herman et al., 2005; Herman et al., 1996). Upon activation of CRHsynthesizing neurons, $\mathrm{CRH}$ is released into the median eminence and subsequently transported via the hypothalamic-hypophyseal portal circulation to the anterior pituitary. Corticotropin-releasing hormone acts on corticotropin-releasing hormone type 1 receptors (CRHR1) on corticotrope cells to release adrenocorticotropic hormone (ACTH) into the systemic circulation (Aguilera, 1998; Aguilera et al., 2004). Adrenocorticotropic hormone acts on melanocortin 2 receptors (MC2R) on cells within the zona fasciculata of the adrenal cortex to stimulate synthesis and release of glucocorticoid hormones (cortisol in humans and fish, corticosterone in other vertebrates) into the systemic circulation (Gallo-Payet, 2016). Glucocorticoids act on intracellular receptors, the glucocorticoid receptor (GR) and the mineralocorticoid receptor (MR) expressed in diverse target tissues including brain, various peripheral organs, and also the immune system, through genomic mechanisms that regulate gene transcription via GR (De Kloet et al., 1998; Hollenberg et al., 1985) and MR (Arriza et al., 1987; De Kloet et al., 1998).

\section{Historical perspectives for interactions between glucocorticoids and monoaminergic uptake/clearance}

Although the sympathetic nervous system and HPA axis responses to stressors are often considered to act independently, it has been clear that they interact in a synergistic way to amplify adaptive, stress- 
related physiological responses. For example, early studies demonstrated that while infusion of cortisol had no effect, by itself, on plasma glucoseconcentrations, when cortisol was infused concurrently with epinephrine, the two compounds had a synergistic effect on plasma glucose concentrations, such that, after $5 \mathrm{~h}$, the rise in plasma glucose concentrations was two-fold greater than the sum of the individual responses (Eigler et al., 1979). This effect was attributed to the ability of cortisol to sustain increases in glucose production induced by epinephrine (i.e., rather than epinephrine-induced changes in glucose clearance or plasma insulin levels) (Eigler et al., 1979). This effect of cortisol was an early example of a class of "permissive" effects or context-dependent effects of glucocorticoid hormones, effects that are now well established in the literature (Sapolsky et al., 2000). A frequently cited example involves the permissive role that glucocorticoids play to allow catecholamines to exert their full actions (Sapolsky et al., 2000), effects that have been documented in vascular and cardiac tissue (Fowler and Cleghorn, 1942; Fritz and Levine, 1951; Grunfeld and Eloy, 1987; Kalsner, 1969; Ramey et al., 1951; Sapolsky and Share, 1994; Schomig et al., 1976; Tanz, 1960). Among the potential mechanisms cited was the ability of glucocorticoids to inhibit catecholamine reuptake(Gibson, 2008; Sapolsky et al., 2000). As will be discussed in detail below, context-dependent effects of glucocorticoids in both the periphery and brain (for review, see Orchinik et al., 2009) may involve inhibition of uptake ${ }_{2}$, subsequently defined at the molecular level as organic cation transporter 3 (OCT3) (Kekuda et al., 1998; Wu et al., 1998) or extraneuronal monoamine transporter (EMT) (Grundemann et al., 1998b).

\section{Rapid nongenomic effects of corticosterone in an amphibian model}

Studies in the model organism, the roughskin newt, Taricha granulosa, over 30 years ago led to the discovery that stress can rapidly (within minutes) suppress sexual behavior (amplectic clasping) of male $T$. granulosa, an effect that is mimicked by corticosterone injection (Boyd and Moore, 1990; Coddington and Moore, 2003; Coddington and Moore, 2001; Moore and Evans, 1999; Moore and Miller, 1984; Moore and Orchinik, 1994; Moore et al., 1995). Subsequent studies using this model system led to identification of a corticosteroid receptor in neuronal membranes. Importantly, steroids, including dexamethasone, that did not effectively compete with corticosterone for binding to the neuronal membrane receptor also failed to inhibit clasping behavior, while steroids that did compete (cortisol, aldosterone) did inhibit clasping behavior (Orchinik et al., 1991). These studies provided the first evidence for a membrane corticosteroid receptor involved in the rapid regulation of behavior.

\section{Co-regulation of DA and 5-HT in the $\mathrm{DMH}$; a clue to novel regulatory}

\section{mechanisms?}

The rapid effects of corticosterone on behavior in T. granulosa led us to explore rapid effects (measured within $20 \mathrm{~min}$ ) of corticosterone on catecholamines in microdissected brain regions. These studies demonstrated that corticosterone increased both serotonin (5-HT) and dopamine (DA) concentrations within the dorsomedial hypothalamus (DMH) (Lowry et al., 2001). This effect was restricted to the $\mathrm{DMH}$, a region that contains monoamine-accumulating cells, collectively referred to as the paraventricular organ, a common feature of the hypothalamus of all nonmammalian vertebrates (Lowry et al., 1996). A remarkable observation in studies of the effects of corticosterone on monoamines of the DMH of T. granulosa was that the tissue concentrations of DA in the DMH were positively correlated with the tissue concentrations of 5-HT within the DMH under a variety of experimental conditions (Lowry et al., 2001), including following injection of corticosterone. 
Similar increases in 5-HT, DA, and norepinephrine were observed in the DMH of rats exposed to a 30min period of restraint stress (Lowry et al., 2003). Again, in this model, DA concentrations in the DMH were highly correlated with 5-HT concentrations in the $\mathrm{DMH}$.

It was recognized at the time that a clear precedent existed for a physiologically relevant co-regulation of DA and 5-HT. Synthesis of DA and 5-HT can occur within the same cellular compartment, e.g., within the epithelial cells of the renal cortical proximal tubules (Vieira-Coelho and Soares-Da-Silva, 1997; Vieira-Coelho and Soares-Da-Silva, 1998). This co-regulation of DA and 5-HT in the kidney was thought to be dependent on uptake of the precursors, L-3,4-dihydroxyphenylalanine (L-DOPA) and L-5hydroxytryptophan (L-5-HTP), and possibly DA and 5-HT via the same transporter complex (Soares-DaSilva and Pinto, 1996).

In renal proximal tubule cells, DA and 5-HT excretion is mediated by specific transport proteins. Organic cation transporter type 1 (OCT1) is believed to mediate the uptake of organic cations including L-DOPA and L-5-HTP, as well as DA and 5-HT from the perivascular spaces around the basolateral cell surface (Breidert et al., 1998; Martel et al., 2000; Martel et al., 1999; Soares-Da-Silva and Pinto, 1996; Zhang et al., 1998). The organic cation transporter type 2 (OCT2) is believed to mediate the secretion of DA and 5-HT from the apical plasma membrane of renal proximal tubule cells (Grundemann et al., 1998a). Expression of OCT2 mRNA is found not only in the kidney, but also in DArich regions of the central nervous system (Grundemann et al., 1997). Interestingly, the transport of ${ }^{3} \mathrm{H}-$ DA and ${ }^{3} \mathrm{H}-5-\mathrm{HT}$ by OCT2 in a stable transfection system is inhibited by corticosterone, with a Ki value of approximately $500 \mathrm{nM}$, a concentration that is well within the physiological range (Grundemann et al., 1998a). Additional corticosterone-sensitive members of the organic cation transporter family are expressed in brain and have been cloned (e.g., ОCT3 (Wu et al., 1998); also called extraneuronal monoamine transporter, EMT (Grundemann et al., 1998b), as described above). Other members of this novel, corticosterone-sensitive family of transporters, belonging to the amphiphilic solute facilitator (ASF) family, exist (e.g., (Martel et al., 2000)), but have not been cloned. Likewise, additional members of this family have been cloned, but have not been functionally characterized (Schomig et al., 1998). Based on the observation that several members of this family of transporters are corticosterone-sensitive and are expressed in brain, it is possible that the rapid effect of corticosterone to induce site-specific accumulation of DA and 5-HT within the DMH is due to inhibition of DA and 5-HT release from the apical extension of DA- and 5-HT-accumulating cells associated with the paraventricular organ (cf. Discussion by (Grundemann et al., 1998a, Grundemann et al., 1998b)). Thus, paraneurons (a term originated by Fujita in 1975; i.e., groups of cells that have not been classified as neurons and yet share certain morphological and functional features with neurons) (Fujita, 1977; Fujita and Kobayashi, 1979) in the DMH may be functionally analogous to the "dopaminehandling" cells within the proximal tubules of the kidney, possibly clearing L-DOPA, catecholamines, 5HTP, 5-HT and related cations from perivascular spaces within the central nervous system and ultimately excreting them into the lumen of the brain for clearance via the cerebrospinal fluid. If this is the case, the DMH may prove to be an excellent model system for studies of rapid effects of stress and glucocorticoid hormones on brain catecholaminergic and serotonergic function.

The study by Lowry et al. (2001) pointed toward functionally uncharacterized DA- and 5-HTaccumulating neurons within the $\mathrm{DMH}$ as a potential target for rapid nongenomic effects of CORT. Similar DA- and 5-HT-accumulating systems are distributed throughout the central and peripheral nervous systems, suggesting that the proposed effects of CORT on these cells play an important role in 
stress-related physiology and behavior. Furthermore, in rat and vole brains, the highest concentrations of CORT binding sites in synaptosomal membrane fractions are found in the hypothalamus (Orchinik et al., 1997; Towle and Sze, 1983). Thus, the hypothalamus may be an important site for rapid, nongenomic effects of CORT in both nonmammalian and mammalian brain.

\section{Glucocorticoid-catecholamine interactions - the role of uptake 2}

Physiologists working in the mid-twentieth century observed that glucocorticoids, either injected or topically applied, in both in vivo and ex vivo preparations, rapidly potentiated the actions of catecholamines in peripheral tissues. These effects occurred within minutes of either injection or topical application of the steroid, and were observed in nictitating membranes, conjunctival vessels, and aortic smooth muscle preparations (Fowler and Chou, 1961; LeComte et al., 1959; Reis, 1960). Such observations led Richard Schayer to state that the potentiation of catecholamine action on microcirculatory smooth muscle is "the most rapid known effect of injected glucocorticoids", occurring within 2-3 min after intravenous injection (Schayer, 1963). These interactions are likely the earliest reports of rapid physiological responses to glucocorticoids, and stimulated a large number of studies to elucidate the mechanisms and sites of glucocorticoid action. Evidence for a direct action of glucocorticoids at the smooth muscle was demonstrated by studies of conjunctival microvessels. Direct subconjunctival application of corticosteroid suspensions rapidly (within $15 \mathrm{~min}$ ) decreased, by 3- to 10-fold, the threshold concentration of norepinephrine required to induce spasm of the precapillary sphincters and metarterioles in both rabbits (Lepri and Cristiani, 1964) and human subjects (Reis, 1960; Lepri and Cristiani, 1964). Similar rapid potentiating effects of a variety of corticosteroids were observed using ex vivo preparations of spirally cut aortic smooth muscle to which steroids and catecholamines were directly applied (Besse and Bass, 1966; Fowler and Chou, 1961). In both studies, the potentiating actions of the corticosteroid were observed within 0$2 \mathrm{~min}$. Corticosterone, aldosterone, androsterone and dehydroepiandrosterone (DHEA) all produced immediate and reversible potentiation of norepinephrine-induced muscle contraction, with corticosterone exerting effects at the lowest concentration (Fowler and Chou, 1961). Hydrocortisone rapidly potentiated both alpha- and beta-adrenergic responses, and potentiation was maintained in aortic strips pretreated with reserpine to deplete catecholamines stored in sympatheticterminals (Besse and Bass, 1966), indicating that the steroid was not acting to release endogenous transmitter, but was somehow increasing the potency of applied catecholamines at the receptor. These studies further demonstrated that, while cocaine-induced blockade of uptake also potentiated norepinephrine-induced contractions, the effects of hydrocortisone were greater than those of cocaine, and effects were additive to those of cocaine. Thus, the mechanism of corticosteroidinduced potentiation was distinct from that of cocaine, suggesting at the time that the steroid was not interfering with norepinephrine clearance. However, studies were published at about this time indicating the existence of a second, cocaine-insensitive, catecholamine uptake system that was inhibited by corticosteroids.

Studies of the transport and metabolism of catecholamines in heart tissue revealed the presence of two distinct uptake processes for epinephrine and norepinephrine. Uptake ${ }_{1}$, a high-affinity $\left(K_{d}=0.27 \mu M\right)$, low-capacity $\left(V_{\max }=1.22 \mathrm{nmol} / \mathrm{min} / \mathrm{g}\right.$ tissue $)$ system; and uptake ${ }_{2}$, a low-affinity $\left(K_{d}=252 \mu \mathrm{M}\right)$, high-capacity $\left(\mathrm{V}_{\max }=100 \mathrm{nmol} / \mathrm{min} / \mathrm{g}\right)$ system (Iversen, 1965). Uptake ${ }_{1}$, termed "neuronal uptake", was inhibited by cocaine and desipramine, while uptake, or "extraneuronal uptake", insensitive to cocaine and desipramine, was inhibited by normetanephrine. Based on its low affinity, uptake ${ }_{2}$ was originally thought to operate only at very high concentrations of substrate. 
However, subsequent studies demonstrated that this transport process operates at all substrate concentrations (Lightman and Iversen, 1969). Importantly, later studies identified additional substrates of uptake ${ }_{2}$, including the $\beta$-adrenergic receptor antagonist isoproterenol, the $\alpha_{2}$-adrenergic receptor agonist clonidine, the monoamines DA, 5-HT, histamine, and the trace amine tyramine (Grohmann and Trendelenburg, 1984). Russ et al. later demonstrated that the neurotoxin 1-methyl-4-

phenylpyridinium (MPP+) is an excellent uptake ${ }_{2}$ substrate (Russ et al., 1992). Because it is not subject to metabolic breakdown or oxidation, MPP+ is commonly used as a substrate to measure monoamine transporter activity.

In the search for more specific inhibitors of uptake ${ }_{2}$, Iversen and Salt (1970) speculated that steroids may potentiate the actions of catecholamines on vascular smooth muscle by inhibiting uptake 2 $^{-}$ mediated catecholamine clearance of the transmitters. They went on to demonstrate that a variety of steroids, including corticosterone, deoxycorticosterone, and $17 \beta$-estradiol inhibit uptake -mediated $^{-}$ clearance of epinephrine and norepinephrine in heart tissue (Iversen and Salt, 1970). Subsequent studies have demonstrated that the ability of corticosteroids to enhance both the vasomotor actions of norepinephrine in vascular smooth muscle and the ionotropic and chronotropic actions in heart muscle were mediated by inhibition of uptake ${ }_{2}$-mediated norepinephrine clearance, thus explicitly linking rapid corticosteroid effects with a nongenomic mechanism (Goldie, 1976; Kalsner, 1969; Kalsner, 1974).

\section{Molecular identification of uptake ${ }_{2}$}

Based on overlapping substrate specificities and inhibitor sensitivities between uptake ${ }_{2}$ and the renal organic cation transporter, OCT2, Grundemann et al. hypothesized that the transporter responsible for uptake ${ }_{2}$ belonged to the same family of transporters, the ASF family. Based on this hypothesis, the group cloned a novel ASF transporter, the "extraneuronal monoamine transporter" (EMT), which displayed uptake ${ }_{2}$-like functional properties (Grundemann et al., 1998b). Cells stably expressing cloned EMT displayed corticosterone-sensitive uptake of the uptake ${ }_{2}$ substrates epinephrine, norepinephrine, 5-HT, tyramine, and MPP+. Like transport mediated by uptake $_{2}$, EMT-mediated norepinephrine uptake was characterized by a high $\mathrm{K}_{\mathrm{m}}(510 \mu \mathrm{M})$ and $\mathrm{V}_{\max }(3.9 \mathrm{nmol} / \mathrm{min} / \mathrm{mg}$ protein), indicating a much lower affinity, but higher capacity for substrate than that of "neuronal uptake". Based upon these properties, EMT and neuronal uptake are expected to display similar rates of transport per cell (Grundemann et al., 1998b). In addition to identifying a key transporter mediating uptake ${ }_{2}$, Grundemann's group also demonstrated: a) that the concentrations of corticosterone required to block EMT-mediated uptake $\left(\mathrm{K}_{\mathrm{i}}=120 \mathrm{nM}\right)$ lay in the physiological range of corticosteroid concentrations; and b) that, in addition to the heart and liver, EMT mRNA was also expressed in the human brain, indicating that, as in peripheral tissues, corticosterone may potentiate monoaminergic neurotransmission in the central nervous system by blocking uptake $2^{-}$ mediated clearance.

During the same period of the cloning of EMT, another group cloned a third member of the organic cation transporter family, OCT3, from rat placenta, and demonstrated that it was identical to EMT (Kekuda et al., 1998; Wu et al., 1998). While both names are still in use, OCT3 is the more common designation. The OCTs (OCT1, OCT2 and OCT3) are structurally similar proteins, though OCT1 and OCT2 are more similar to each other (70\% identical, $84 \%$ similar) than either is to OCT3 (50\% identical, $70 \%$ similar to each) (Grundemann et al., 1999). Each transporter possesses 12

putative transmembrane domains (Kekuda et al., 1998). Functionally, OCT1, OCT2, and OCT3 all 
mediate bidirectional, $\mathrm{Na}^{+-i n d e p e n d e n t ~ t r a n s p o r t ~ o f ~ m o n o a m i n e s ~ a n d ~ o t h e r ~ o r g a n i c ~ c a t i o n s, ~ t h o u g h ~}$ each transporter has a unique substrate specificity (for review, see Schomig et al., 2006). Importantly, transport mediated by all of the OCTs is inhibited by corticosterone, though sensitivity varies markedly among the three, and can vary from species to species (reviewed in Koepsell et al., 2007). Among the human transporters, OCT3 displays the greatest corticosterone sensitivity, with an $\mathrm{IC}_{50}$ of $0.2 \mu \mathrm{M}$, compared with $10 \mu \mathrm{M}$ for OCT1 and $30 \mu \mathrm{M}$ for OCT2 (Arndt et al., 2001; Grundemann et al., 1998a, Grundemann et al., 1998b; Hayer-Zillgen et al., 2002; Wu et al., 1998). In the rat, OCT1 is the least corticosterone-sensitive, with an $\mathrm{IC}_{50}$ of $150 \mu \mathrm{M}$, while OCT2 and OCT3 display similar corticosterone sensitivities ( $\mathrm{IC}_{50}=4$ and $5 \mu \mathrm{M}$, respectively) (Schomig et al., 2006). Importantly, the measured sensitivity of the transporters also appears to depend on the preparation. We have demonstrated, in ex vivo studies of rat hypothalamictissue, corticosterone inhibition of OCT3-mediated uptake at concentrations similar to those reported for human OCT3 $\left(\mathrm{IC}_{50}=0.03-0.2 \mu \mathrm{M}\right)(\mathrm{Gasser}$ et al., 2006; Hill et al., 2011).

Corticosterone-induced inhibition of OCT-mediated transport is rapid and appears to involve direct interaction of the steroid with the transporter at a specific site. Volk et al. (2003)studied OCT2mediated transport by measuring substrate-induced currents using patch clamp of Xenopus oocytes exogenously expressing rat OCT2. In these studies, corticosterone inhibited OCT2-mediated currents within $30 \mathrm{~s}$ of application (Volk et al., 2003). The ability of corticosterone and other steroids to inhibit OCT-mediated transport appears to involve direct binding with the transporter in a pocket deep within the substrate-binding cleft. The corticosterone binding sites in OCT1 and OCT2 were identified by the construction of chimeric transporters, interchanging segments of rOCT1 and rOCT2, and measuring both the transport activity and its sensitivity to inhibition by corticosterone. By this method, three key amino acids in the 10th transmembrane domain (Ala443, Leu447, and Gln448 in rOCT1 and Ile443, Tyr447, and Glu448 in rOCT2) were identified as critically involved in corticosteroid-induced inhibition of transport (Gorboulev et al., 2005). When these three amino acids from rOCT2, which are identical in rOCT2 and rOCT3, are introduced into $\mathrm{rOCT} 1$, they decrease the $\mathrm{IC}_{50}$ for corticosterone inhibition of rOCT1 from $150 \mu \mathrm{M}$ to that of rOCT2, i.e., $4 \mu \mathrm{M}$. Subsequent studies and structural modeling provided evidence that these amino acids are found in the innermost cavity of a substrate-binding cleft in the transporter that alternates between inwardly- and outwardly-facing during transport (Fig. 1) (Volk et al., 2009). Thus, corticosterone appears to directly bind to OCT3, making the inhibition of OCTmediated transport by corticosterone a truly nongenomic, GR-independent phenomenon. This is borne out in studies of corticosteroid-induced inhibition of uptake in bronchial tissue, which is rapid, GRindependent, and insensitive to inhibitors of transcription (Horvath et al., 2001). 

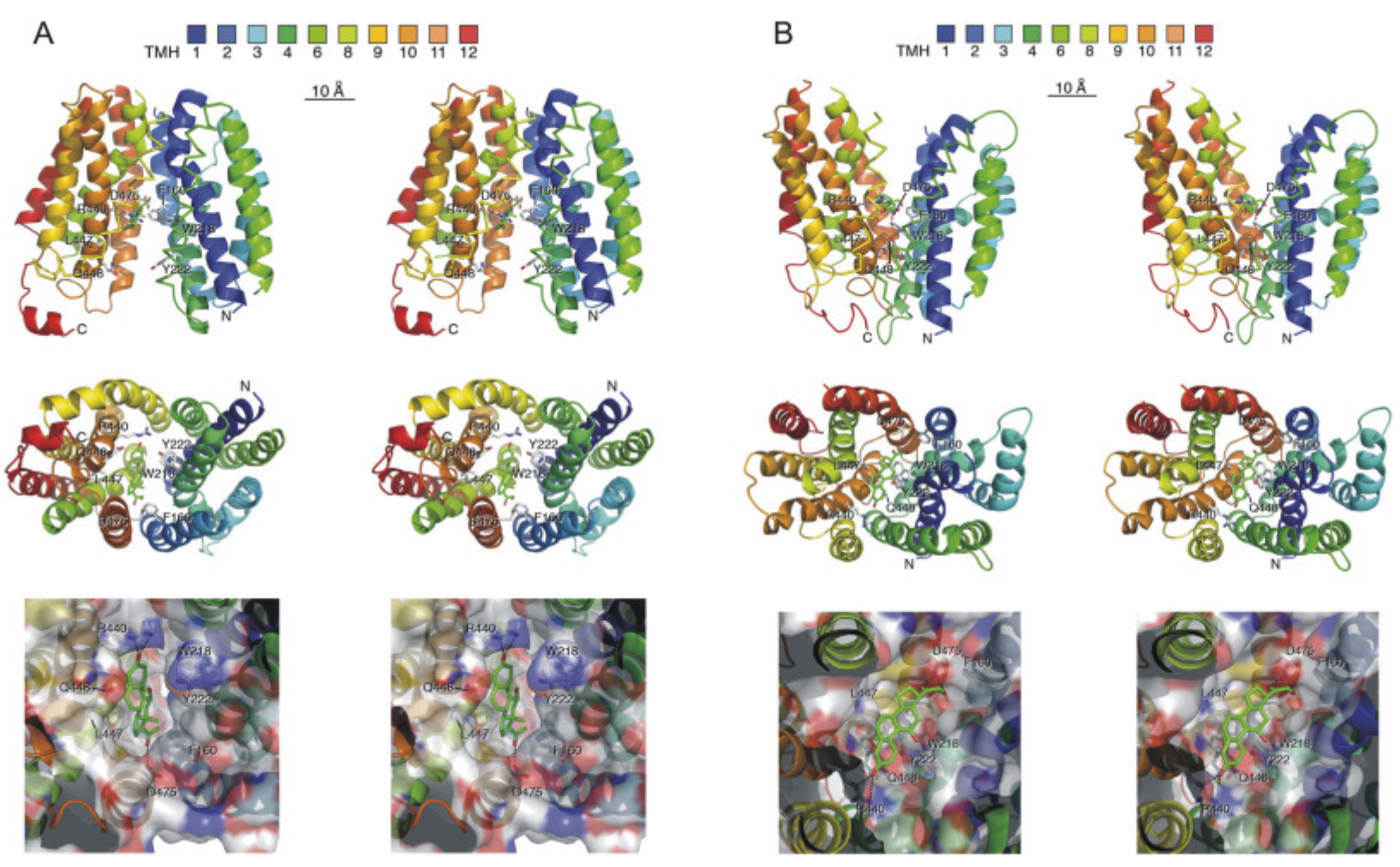

Fig. 1. Simulations of corticosterone binding to the inward-facing (A) and outward-facing (B) substrate clefts of rOCT1. Docking simulations were performed in which residues Leu447 and Phe160 were selected as direct docking sites using radii of $5 \AA$ around these residues. A) Docking of corticosterone to the inward-facing substrate cleft of rOCT1. B) Docking of corticosterone to the outward-facing substrate cleft of rOCT1. In both A) and B), stereopictures are presented showing a side view with cytosolic $\mathrm{N}$ and $\mathrm{C}$ termini (top) and views into the binding cleft from the A) cytosolic side (middle and bottom) and B) extracellular side (middle and bottom). The colors of the twelve predicted transmembrane $\alpha$-helices(TMH) are indicated. The amino acid side chains of Phe160, Trp218, Tyr222, Arg440, Leu447, GIn448, and Asp475 are shown as sticks. The bottom shows a magnification in which the van der Waals surface of the binding cleft is colored according to amino acid polarity, with hydrophobic residues marked in gray, polar uncharged residues in green, negatively charged residues in red, and positively charged amino acids in blue. Their positions are indicated by numbers. Putative hydrogen bonds between corticosterone (highest docking energy) and amino acids of rOCT1 are indicated by stippled lines. Amino acid residues that are critical for corticosterone binding to rOCT1, including Phe160, Trp218, Arg440, and Asp475, but not L447 and GIn448, are conserved in rOCT2, rOCT3, and hOCT3. Adapted, with permission, from Volk et al., 2009.

Together, these studies suggest that uptake ${ }_{2}$-like transport of monoamines is mediated by a family of transporters. While OCT3-mediated monoamine transport appears to be the most sensitive to inhibition by corticosteroids, the presence of species differences in steroid sensitivity, together with variations in the reported IC50s depending on the preparation (native transporter expression versus transporter exogenously expressed in cell lines), make definitive determination of relative steroid sensitivity among OCT1-3 difficult. It is clear, at least, that OCT1 is much less corticosterone-sensitive than either OCT2 or OCT3. However, roles for OCT2 in mediating the effects of stress-level corticosterone cannot be ruled out. Indeed, a recent study showed that genetic deletion of OCT2, which is expressed in the brain, including in several stress-related brain regions, resulted in increased HPA axisresponses to acute stress, suggesting potential roles in corticosterone-dependent processes (Courousse et al., 2015; Courousse and Gautron, 2015). More recently, an additional uptake ${ }_{2}$-like transporter, the plasma membrane monoamine transporter (PMAT), has been identified, and its expression in the brain has been described (Engel et al., 2004). Like OCT3, PMAT is a multispecific monoamine transporter, but PMAT-mediated transport is highly selective for DA and 5-HT. In direct comparisons, PMAT and OCT3 displayed comparable DA and histamine uptake (Vmax), while 
PMAT displayed significantly greater uptake of 5-HT, and OCT3 displayed greater uptake of norepinephrine and epinephrine (Duan and Wang, 2010). Transport mediated by PMAT is markedly less sensitive to inhibition by corticosteroids, with a reported $\mathrm{IC}_{50}$ of $450 \mu \mathrm{M}$, well outside the physiological range (Engel et al., 2004). Thus, while it is now clear that "uptake " activity is mediated by a group of at least 4 transporters, and that any of them may contribute to effects of supraphysiological corticosteroid concentrations, OCT3 (and perhaps OCT2) are the most likely candidates for mediating rapid effects of corticosterone in the physiological range.

\section{Distribution of OCT3 in rat brain}

To understand the potential roles of this corticosterone-sensitive monoamine clearance mechanism in the regulation of monoaminergic neurotransmission and behavior, and its potential contribution to corticosteroid actions on behavior, we examined the rostrocaudal distribution of OCT3 in the male rat brain using immunohistochemistry (Gasser et al., 2009). The transporter is expressed, at least at low levels, in nearly all brain regions. It is found in white matter tracts, where it occurs in cells morphologically similar to oligodendrocytes, and broadly in grey matter areas. Perikarya expressing OCT3 are found in ependymal and subependymal cells lining the ventricles. The transporter is densely expressed in granule cellneurons, including those in the cerebellum, olfactory bulb, subventricular zones, and retrosplenial cortex. This is consistent with studies demonstrating that OCT3 mediates the uptake of the neurotoxin MPP+ in cultured cerebellar granule neurons (Shang et al., 2003). High densities of OCT3-expressing fibers and/or cells are also found in circumventricular zones, including the subcommissural organ, vascular organ of the lamina terminalis, area postrema, and median eminence (Gasser et al., 2009; Vialou et al., 2004).

An important question for future research is whether or not OCT3 (and/or OCT1 or OCT2) is expressed in tanycytes, which have been implicated in transport of signaling molecules between neurons and extra-neuronal spaces, the cerebrospinal fluid, and the hypothalamic-hypophyseal portal circulation (Goodman and Hajihosseini, 2015), or other monoamine-accumulating ependymal and subependymal cells that have been identified in the rodent medial hypothalamus (Lowry et al., 1996). Tanycytes contain monoamines, including serotonin (Sladek, Jr. and Sladek Jr and Sladek, 1978), have been implicated in hypothalamic glucosensing (Elizondo-Vega et al., 2015) and have recently been identified as a population of neural progenitor cells within appetite/energy-balance regulating centers of the postnatal and adult hypothalamus (Goodman and Hajihosseini, 2015; Haan et al., 2013). Studies examining the cellular and subcellular distributions of OCT3 suggest that this transporter plays a variety of roles in regulating monoaminergic neurotransmission. Expression of OCT3 has been demonstrated in neurons (Cui et al., 2009; Gasser et al., 2009; Hill et al., 2011; Shang et al., 2003; Vialou et al., 2004), astrocytes (Cui et al., 2009; Gasser et al., 2017; Takeda et al., 2002), microglia (He et al., 2017), oligodendrocytes (Gasser et al., 2009), ependymal (Gasser et al., 2006; Gasser et al., 2009) and vascular endothelial cells (Li et al., 2013) in the brain. Thus, OCT3 is positioned to regulate extracellular monoamine concentrations in a variety of microenvironments in the central nervous system.

The exact role of OCT3 in regulation of monoaminergic neurotransmission depends critically on the subcellular localization of the transporter, particularly with respect to transmitter release sites and receptors. In a recent study, we used immunofluorescence and immunoelectron microscopy to identify the cellular and subcellular distribution of OCT3 within the amygdala of both rats and mice (Gasser et al., 2017). Dense OCT3 immunoreactivity was observed in plasma membranes of both neurons and 
astrocytic glial cells. The transporter was observed in neuronal somata, as well as in axonal and dendriticmembrane profiles, suggesting that OCT3 may regulate the extent to which monoamines activate pre- and post-synaptic receptors, and therefore the neuromodulatory effects of monoamines. Interestingly, many of the OCT3-expressing axonal profiles displayed structural characteristics of noradrenergic terminals, indicating that presynaptic reuptake of norepinephrine may involve OCT3 as well as the norepinephrine transporter (NET). Dense OCT3 expression was also observed in the plasma membranes of astrocyte processes that ensheathed both axospinous and axodendritic processes, suggesting another mechanism by which OCT3 may modulate monoaminergic transmission.

In addition to plasma membrane sites, OCT3 was also observed associated with endomembranes, including mitochondrial membranes, with particularly strong expression in the outer nuclear membranes of both neurons and astrocytes (Gasser et al., 2017), indicating that, in addition to regulating extracellular monoamine levels, ОСТ3 may also determine the intracellular localization and/or actions of monoamines. Specifically, intracellular OCT3 may gate access of monoamines to metabolizing enzymes, including monoamine oxidase (MAO) and catechol-O-methyl transferase (COMT), which have been identified in the nuclear envelope (Muller and Da, 1977; Myohanen and Mannisto, 2010; Ulmanen et al., 1997) as well as in mitochondria. Another potential role for nuclear expression of OCT3 is suggested by recent studies demonstrating that adrenergic receptorscan be found localized to inner nuclear membranes in cardiomyocytes, and that norepinephrine-induced activation of these receptors is mediated by OCT3 (Dahl et al., 2015; Vaniotis et al., 2013; Wu et al., 2014; Wu and O'Connell, 2015). A similar role for OCT3 was recently demonstrated by Irranejad et al. (2017). In these studies, OCT3-mediated transport was required for activation of betaadrenoceptors localized to the Golgi endomembranes.

\section{Interactions between stress, glucocorticoids, and}

\section{norepinephrine/epinephrine: the role of OCT3}

Although early studies confirmed the presence of

uptake $_{2}$ of norepinephrine and normetanephrine in hypothalamic and striatal slices, demonstrating that this uptake system was present in the brain (Hendley et al., 1970; Shaskan and Snyder, 1970), most studies that have examined corticosteroid-sensitive norepinephrine transport have been conducted in vascular smooth muscle. These studies have clearly demonstrated that corticosteroidsrapidly increase extracellular norepinephrine concentrations, potentiating physiological responses to norepinephrine in a GR- and transcription-independent fashion (Horvath et al., 2003). The only study to examine a role for OCT3 in regulating extracellular norepinephrine concentrations used microdialysis to show that normetanephrine, a competitive inhibitor of OCT3, potentiated the effects of low-dose venlafaxine on extracellular norepinephrine levels in the hippocampus (Rahman et al., 2008). In this study, normetanephrine also potentiated desipramineinduced decreases in immobility in the tail suspension test. Corticosteroid-induced inhibition of OCT3 would be expected to act in a similar fashion, though this has not been directly examined. This mechanism may in part underlie the ability of corticosterone to enhance the effects of electric footshock on extracellular norepinephrine concentrations in the basolateral amygdala and consolidation of memory for inhibitory avoidance (McReynolds et al., 2010). In these studies, corticosterone pre-treatment potentiated subthreshold footshock-induced increases in norepinephrine levels within the basolateral amygdala (BLA) and enhanced inhibitory avoidance memory. 


\section{Interactions between stress, glucocorticoids, and dopamine: the role of OCT3}

Stress and glucocorticoids have been reported to acutely increase extracellular DAconcentrations, particularly in the striatum, and these effects have been linked to the influence of stress on the abuse of cocaine and other drugs. Electric footshock increased extracellular DA in the shell, but not the core, of the nucleus accumbens (Kalivas and Duffy, 1995). The role of glucocorticoids in stress-induced increases in extracellular DA is supported by studies in which intravenous infusion of corticosterone resulted in significant increases in striatal DA concentrations measured by microdialysis. Interestingly, these effects of corticosterone were observed when the infusion occurred in the dark period (when DA neurons are most active), but not when the infusion occurred during the light period. A similar effect was observed when corticosterone was administered in the drinking water. Corticosterone ingestion during the dark phase, but not during the light, led to increases in extracellular DA in the striatum (Piazza et al., 1996). The timing of glucocorticoid-induced increases in DA in these studies is not clear as the temporal resolution of microdialysis is limited. Greater temporal resolution is provided by electrochemical studies. Mittleman and colleagues used chronoamperometry to compare the acute effects of corticosterone administration on nucleus accumbens DA to those of acute amphetamine. Both treatments led to significant and comparable increases in extracellular DA. Interestingly, while the amphetamine-induced increase in extracellular DA was observed within seconds of injection, the effect of corticosterone was delayed, with a latency of 16-18 min (Mittleman et al., 1992). This differential timing is consistent with the proposed mechanisms of action of the two treatments, with amphetamine inducing DA release via reverse transport, and corticosterone potentially reducing clearance of tonically released DA. In one of the first studies to provide evidence for glucocorticoid-sensitive DA clearance in the central nervous system, Gilad et al. demonstrated that the synthetic glucocorticoid methylprednisolone decreased DA uptake by septal synaptosomes within 10 min of application (Gilad et al., 1987).

The finding that OCT3 is expressed in the nucleus accumbens (Gasser et al., 2009) suggests that inhibition of this transporter may underlie previously described effects of glucocorticoids on extracellular DA concentrations and indicates that DA clearance in this region is not mediated exclusively by the DA transporter (DAT). This poses an interesting mechanism by which glucocorticoids may interact with the effects of cocaine on dopaminergic neurotransmission, contributing to the effects of stress on drug-seeking behavior. Our group has provided evidence consistent with this mechanism by examining the interaction of subthreshold doses of cocaine with glucocorticoids in rodent models of addiction (Graf et al., 2013; McReynolds et al., 2017). In one set of studies (Graf et al., 2013), rats were trained to self-administer cocaine under short-access conditions ( $2 \mathrm{~h}$ daily access to the drug), followed by extinction training, in which lever presses no longer result in delivery of cocaine. These animals, as compared to those trained under long-access conditions, are relatively resistant to stress- or cocaine-induced reinstatement of drug seeking behavior. Specifically, neither injection of a low dose of cocaine $(2.5 \mathrm{mg} / \mathrm{kg})$, nor exposure to $15 \mathrm{~min}$ of intermittent electric footshock stress, led to significant reinstatement of drug-seeking behavior (lever presses despite the lack of cocaine delivery). However, the combination of these two stimuli (low dose cocaine preceded, 40 min earlier, by electric footshock) induced robust reinstatement (Graf et al., 2013).

Similarly, intraperitoneal injectionof corticosterone at a concentration that reproduces stress levels of the steroid, did not by itself lead to reinstatement, but potentiated low-dose cocaine-induced reinstatement, an effect that was not blocked by pretreatment with RU-38486, an inhibitor of 
the glucocorticoid receptor, but was blocked by intra-nucleus accumbens injection of fluphenazine, a DA receptor antagonist (Graf et al., 2013). Thus, corticosterone-induced potentiation appears to be mediated by a GR-independent, nongenomic mechanism involving local striatal DA signaling. The hypothesis that corticosterone-induced potentiation of reinstatement involves inhibition of OCT3mediated clearance was supported by the demonstration that OCT3-like immunoreactivity was observed on both medium-spiny neurons and astrocytes in the nucleus accumbens, suggesting that OCT3 regulates extracellular DA concentrations by mediating postsynaptic and glial uptake, and that direct, intra-nucleus accumbens injection of either corticosterone or normetanephrine, a competitive inhibitor of OCT3, potentiated low-dose cocaine-induced reinstatement (Graf et al., 2013).

We examined potential interactions of corticosterone and cocaine in the regulation of nucleus accumbens DA using microdialysis. These studies demonstrated that, while low-dose cocaine alone had no effect on extracellular DA concentrations in the nucleus accumbens, the same dose of cocaine induced significant increases in extracellular DA when it was preceded by systemic corticosterone injection (Graf et al., 2013). While these results are consistent with corticosterone inhibition of DA clearance, increases in DA measured by dialysis may be the result of increased release, decreased metabolism, or decreased clearance. To directly assess the effects of corticosterone on DA clearance, we used in vivo fast-scan cyclic voltammetry (FSCV), a technique that measures both release and clearance of DA on a millisecond time-scale. Corticosterone decreased the rate of DA clearance following electrically stimulated release in the nucleus accumbens of anesthetized animals after blockade of DAT. These studies revealed, for the first time, the presence of DAT-independent, corticosterone-sensitive DA clearance in vivo (Graf et al., 2013). In subsequent studies, we examined the effect of corticosterone on naturally-occurring DA transients in the nucleus accumbens of awake and behaving rats using FSCV. Systemic injection of low-dose cocaine alone had no effect on the amplitude or duration of accumbens DA transients, but robustly increased these measures when injected after systemic administration of corticosterone. Surprisingly, administration of corticosterone alone induced small but significant increases in both the magnitude and duration of these DA transients, demonstrating that corticosterone-induced decreases in DA clearance can be observed without blockade of the high-affinity clearance mechanism, and suggesting that the corticosteronesensitive transporter contributes significantly to the shaping of dopaminesignals in vivo (Wheeler et al., 2017).

To confirm a role of OCT3 in corticosterone-induced potentiation of cocaine-primed reinstatement, we examined the interaction of corticosterone and cocaine in the reinstatement of cocaine conditioned place preference (CPP) in wild type mice, and transgenic OCT3-deficient mice. These mice express a truncated form of OCT3, and lack OCT3-mediated transport activity (Zwart et al., 2001). Systemic administration of either corticosterone or normetanephrine potentiated reinstatement of CPP in response to a previously subthreshold dose of cocaine in wild type mice but had no effect in OCT3deficient mice (McReynolds et al., 2017).

An intriguing distribution of OCT3 in the greater amygdaloid complex suggests a potential role for OCT3 in stress-dependent dopaminergic regulation of amygdala output. Hill and Gasser demonstrated that ОСТ3 expression was highly enriched in the intercalated cell (ITC) groups of the amygdala (Hill and Gasser, 2013). These groups consist primarily of striatal-like, $y$-aminobutyric acid (GABA)ergic neurons that project to the basolateral amygdaloid complex, and potently regulate neurotransmission and plasticity involved in the consolidation of fear memory (Pare et al., 2004). The ITCs are densely 
innervated by dopaminergic projections from the ventral tegmental area (VTA), and densely express D1 receptors (Marowsky et al., 2005). Dopamine, acting through D1 receptors, inhibits ITC GABAergic neurons, resulting in disinhibition of the BLA and central nucleus of the amygdala(CeA) (Marowsky et al., 2005). The dense expression of both OCT3 and D1 receptors on ITC GABAergic neurons suggests that, under baseline conditions, DA levels are kept low via high activity of OCT3. During stress, corticosterone, by inhibiting OCT3-mediated clearance, would be expected to lead to increases in extracellular DA concentrations, which would, by activating local D1 receptors, inhibit ITC activity, thus, disinhibiting amygdala output.

\section{Interactions between stress, glucocorticoids, and serotonin: the role of OCT3}

Studies in T. granulosa showing that corticosterone induced rapid increases in tissue concentrations of 5-HT within the DMH led us to explore the effects of local inhibition of OCTs on extracellular 5-HT concentrations within the rat DMH. Infusion of the OCT blocker, decynium 22, via the microdialysis probe, into the $\mathrm{DMH}$, dose dependently increased 5-HT concentrations in the DHM (Feng et al., 2005). In a subsequent study, we demonstrated that similar responses were observed following local administration of corticosterone into the rat $\mathrm{DMH}$, but this effect was context dependent (i.e., observed in rats with peripheral administration of the 5-HT-releasing drug, fenfluramine, but not in vehicle-treated controls), an effect consistent with the hypothesis that corticosterone inhibits 5-HT clearance in the DMH (Feng et al., 2009). Finally, we demonstrated that increases in extracellular 5-HT following administration of decynium 22 were exaggerated in rats exposed to restraint stress, relative to vehicle-treated controls (Feng et al., 2010). A role for OCT3 in these effects in the $\mathrm{DMH}$ was supported by demonstration that ex vivo histamine accumulation in $\mathrm{DMH}$ tissue could be inhibited by 5-HT, corticosterone, decynium 22, and estradiol, consistent with OCT3 pharmacology (Gasser et al., 2006). Although the physiological and behavioral consequences of OCT3/5-HT interactions in the DMH are not known, they may play a role in negative feedback regulation of the HPA axis (Stamper et al., 2017; Stamper et al., 2015).

Elegant studies by Lynnette Daws and colleagues, using high speed chronoamperometry, demonstrated a low affinity, high capacity 5-HT clearance mechanism in the rat hippocampus after pharmacological blockade of the sodium-dependent, high-affinity, low-capacity 5-HT transporter SERT (Daws et al., 2005). Subsequently, the same group demonstrated that in mice lacking SERT, the same 5$\mathrm{HT}$ clearance mechanism was evident and was blocked by local application of decynium 22 or corticosterone (Baganz et al., 2008), suggesting a role for OCT3 in 5-HT reuptake in hippocampus. The relative contribution of OCT3, relative to SERT or other transporters, to 5-HT clearance under baseline or stress conditions is not known and will require further study. Consistent with the hypothesis that OCT3 inhibition is involved in stress-induced alterations in serotonin clearance, further studies in the Daws laboratory demonstrated that OCT3 expression and function were decreased in the hippocampi of mice exposed to repeated swim stress (Baganz et al., 2010).

\section{Role of OCT3 in histamine clearance}

Histamine is a powerful neuromodulator, as well as a regulator of immune processes and vascular tone in the central nervous system (Gross, 1981; Haas et al., 2008; Jutel et al., 2006). In contrast to 5-HT and the catecholamines, a high-affinity transporter for histamine has not been identified. Thus, OCT3 and

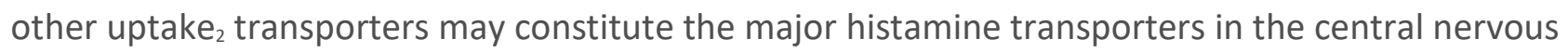


system and in peripheral tissues. Indeed, previous studies have demonstrated that OCT3 mediates histamine uptake by peripheral immune cells (Nakamura et al., 2017; Schneider et al., 2005). In the central nervous system, recent studies have indicated roles for OCT3 and PMAT in the uptake of histamine by cultured astrocytes (Yoshikawa et al., 2013). The specific roles of various uptake ${ }_{2}$ transporters in the clearance of extracellular histamine, and the effects of corticosterone on histaminergic neurotransmission represent important areas for future study.

\section{Implications and future directions}

Since the description of a corticosteroid-sensitive catecholamine clearance system (uptake e $_{2}$ in cardiovascular tissue in the 1960s, and the identification of the multi-specific, corticosteronesensitive monoamine transporter OCT3 as a major mediator of uptake $\mathrm{O}_{2}$, it has become clear that this transport system also contributes significantly to monoamine transport in the central nervous system. Despite these advances, the contribution of OCT3, relative to sodium-dependent, high affinity, low capacity monoamine transporters, or other transporters, to monoamine clearance under baseline or stress conditions is not known and developing a clear answer to this question will require development of new methodological approaches and further study. The demonstration that OCT3 and other uptake ${ }_{2}$-like transporters are expressed in the brain has profound implications for our understanding of the mechanisms that regulate monoaminergic neurotransmission. In areas where OCT3 is expressed, the clearance of monoamines will be, at least in part, inhibited under conditions of elevated corticosteroid hormones, including during times of acute and chronic stress. The studies described here have revealed a small number of pathways in which corticosteroid-induced inhibition of OCT3-mediated monoamine transport regulates monoamine clearance and behavior, acting through rapid, nongenomic mechanisms. Because of its widespread distribution in the brain, and its expression in multiple cell types and subcellular locations, it is very likely that more pathways and behaviors regulated in part by OCT3 will be described in the future. Key outstanding questions remain. The precise roles of OCT3 in mediating monoamine clearance are not fully described. This will require ultrastructural studies that examine the relative localizations of OCT3 and the uptake transporters NET, DAT, and SERT. In addition, a greater understanding of the effects of OCT-mediated monoamine transport, and its inhibition by corticosteroids, on activation of the receptors for monoamines requires knowledge of the proximity of OCT3 to these receptors. Due to its low affinity and high capacity, OCT3 has the potential to limit the physical spread of monoamines to nearby receptors and, when inhibited by steroids, to enhance their activation. Future studies must test these hypotheses. In the absence of specific inhibitors of OCT3, the contribution of the transporter to stress- and glucocorticoid-induced physiological and behavioral responses must be explored using targeted genetic approaches, and the search for specific inhibitors must continue. Despite the gaps in our knowledge, it is clear that OCT3 represents a cellular mechanism by which stress, through elevation of glucocorticoid hormones and rapid, nongenomic actions, may exert powerful modulatory influence over the actions of norepinephrine, DA, 5-HT and histamine and thus over physiological and behavioral responses to these monoamines.

\section{Acknowledgements}

Dr. Paul J. Gasser is supported by the National Institutes of Health (grant number R01DA032895), and the Charles E. Kubly Mental Health Research Center. Dr. Christopher A. Lowry is supported by the National Institutes of Health (grant number R21 MH116263), the Department of the Navy, Office of Naval Research Multidisciplinary University Research Initiative (MURI) Award (grant number N0001415-1-2809), Department of Veterans Affairs Office of Research and Development (VA-ORD) RR\&D Small 
Projects in Rehabilitation Research (SPiRE) (I21) (grant number 1 I21 RX002232-01), the Colorado Clinical and Translational Sciences Institute (CCTSI) Center for Neuroscience (grant number CNSTT-15145), the Colorado Department of Public Health and Environment (CDPHE; grant number DCEED-3510), and the Alfred P. Sloan Foundation (grant number G-2016-7077). Christopher A. Lowry serves on the Scientific Advisory Board of Immodulon Therapeutics Ltd.

Recommended articlesCiting articles (0)

References

Aguilera, 1998. G. Aguilera Corticotropin releasing hormone, receptor regulation and the stress response. Trends Endocrinol. Metab., 9 (1998), pp. 329-336

Aguilera et al., 2004. G. Aguilera, M. Nikodemova, P.C. Wynn, K.J. Catt. Corticotropin releasing hormone receptors: two decades later. Peptides, 25 (2004), pp. 319-329

Arndt et al., 2001. P. Arndt, C. Volk, V. Gorboulev, T. Budiman, C. Popp, I. UlzheimerTeuber, A. Akhoundova, S.Koppatz, E. Bamberg, G. Nagel, H. Koepsell. Interaction of cations, anions, and weak base quinine with rat renal cation transporter rOCT2 compared with rOCT1. Am. J. Physiol. Ren. Physiol., 281 (2001), pp. F454-F468

Arriza et al., 1987. J.L. Arriza, C. Weinberger, G. Cerelli, T.M. Glaser, B.L. Handelin, D.E. Housman, R.M. Evans. Cloning of human mineralocorticoid receptor complementary DNA: structural and functional kinship with the glucocorticoid receptor. Science, 237 (1987), pp. 268-275

Baganz et al., 2008. N.L. Baganz, R.E. Horton, A.S. Calderon, W.A. Owens, J.L. Munn, L.T. Watts, N. KoldzicZivanovic, N.A. Jeske, W. Koek, G.M. Toney, L.C. Daws. Organic cation transporter 3: keeping the brake on extracellular serotonin in serotonin-transporter-deficient mice. Proc. Natl. Acad. Sci. U. S. A., 105 (2008), pp. 18976-18981

Baganz et al., 2010. N. Baganz, R. Horton, K. Martin, A. Holmes, L.C. Daws. Repeated swim impairs serotonin clearance via a corticosterone-sensitive mechanism: organic cation transporter 3 , the smoking gun. J. Neurosci., 30 (2010), pp. 15185-15195

Besse and Bass, 1966. J.C. Besse, A.D. Bass. Potentiation by hydrocortisone of responses to catecholamines in vascular smooth muscle. J. Pharmacol. Exp. Ther., 154 (1966), pp. 224-238

Boyd and Moore, 1990. S.K. Boyd, F.L. Moore. Evidence for GABA involvement in stress-induced inhibition of male amphibian sexual behavior. Horm. Behav., 24 (1) (1990), pp. 128-138

Breidert et al., 1998. T. Breidert, F. Spitzenberger, D. Grundemann, E. Schomig. Catecholamine transport by the organic cation transporter type 1 (OCT1). Br. J. Pharmacol., 125 (1998), pp. 218-224

Coddington and Moore, 2001. E.J. Coddington, F.L. Moore. Corticosterone suppresses amphibian reproductive behavior by modifying specific sensorimotor processing pathways. Soc. Neurosci.

Abstr., 27 (957) (2001), p. 12

Coddington and Moore, 2003. E. Coddington, F.L. Moore. Neuroendocrinology of context-dependent stress responses: vasotocin alters the effect of corticosterone on amphibian behaviors. Horm.

Behav., 43 (2003), pp. 222-228

Courousse and Gautron, 2015. T. Courousse, S. Gautron. Role of organic cation transporters (OCTs) in the brain. Pharmacol. Ther., 146 (2015), pp. 94-103 
Courousse et al., 2015. T. Courousse, A. Bacq, C. Belzung, B. Guiard, L. Balasse, F. Louis, A.M. le

Guisquet, A.M. Gardier, A.H. Schinkel, B. Giros, S. Gautron. Brain organic cation transporter 2 controls response and vulnerability to stress and GSK3beta signaling. Mol. Psychiatry, 20 (2015), pp. 889-900

Cui et al., 2009. M. Cui, R. Aras, W.V. Christian, P.M. Rappold, M. Hatwar, J. Panza, V. Jackson-

Lewis, J.A.Javitch, N. Ballatori, S. Przedborski, K. Tieu. The organic cation transporter-3 is a pivotal modulator of neurodegeneration in the nigrostriatal dopaminergic pathway. Proc. Natl. Acad. Sci. U. S. A., 106 (2009), pp. 8043-8048

Dahl et al., 2015. E.F. Dahl, C.D. Wright, T.D. O'Connell. Quantification of catecholamine uptake in adult cardiac myocytes. Methods Mol. Biol., 1234 (2015), pp. 43-52

Daws et al., 2005. L.C. Daws, S. Montanez, W.A. Owens, G.G. Gould, A. Frazer, G.M. Toney, G.A. Gerhardt. Transport mechanisms governing serotonin clearance in vivo revealed by high-speed chronoamperometry. J. Neurosci. Methods, 143 (2005), pp. 49-62

De Kloet et al., 1998. E.R. De Kloet, E. Vreugdenhil, M.S. Oitzl, M. Joels. Brain corticosteroid receptor balance in health and disease. Endocr. Rev., 19 (1998), pp. 269-301

Duan and Wang, 2010. H. Duan, J. Wang. Selective transport of monoamine neurotransmitters by human plasma membrane monoamine transporter and organic cation transporter 3. J. Pharmacol. Exp. Ther., 335 (2010), pp. 743-753

Eigler et al., 1979. N. Eigler, L. Sacca, R.S. Sherwin. Synergistic interactions of physiologic increments of glucagon, epinephrine, and cortisol in the dog: a model for stress-induced hyperglycemia. J. Clin. Invest., 63 (1979), pp. 114-123

Elizondo-Vega et al., 2015. R. Elizondo-Vega, C. CortesCampos, M.J. Barahona, K.A. Oyarce, C.A. Carril, M.A.Garcia-Robles. The role of tanycytes in hypothalamic glucosensing. J. Cell. Mol. Med., 19 (2015), pp. 1471-1482

Engel et al., 2004. K. Engel, M. Zhou, J. Wang. Identification and characterization of a novel monoamine transporter in the human brain. J. Biol. Chem., 279 (2004), pp. 50042-50049

Feng et al., 2005. N. Feng, B. Mo, P.L. Johnson, M. Orchinik, C.A. Lowry, K.J. Renner. Local inhibition of organic cation transporters increases extracellular serotonin in the medial hypothalamus. Brain Res., 1063 (2005), pp. 69-76

Feng et al., 2009. N. Feng, M. Telefont, K. Kelly, M. Orchinik, G.L. Forster, K.J. Renner, C.A. Lowry. Local perfusion of corticosterone in the rat medial hypothalamus potentiates D-fenfluramine-induced elevations of extracellular 5-HT concentrations. Horm. Behav., 56 (2009), pp. 149-157

Feng et al., 2010. N. Feng, C.A. Lowry, J.L. Lukkes, M. Orchinik, G.L. Forster, K.J. Renner. Organic cation transporter inhibition increases medial hypothalamic serotonin under basal conditions and during mild restraint. Brain Res., 1326 (2010), pp. 105-113

Fowler and Chou, 1961. N.O. Fowler, N.H. Chou. Potentiation of smooth muscle contraction by adrenal steroids. Circ. Res., 9 (1961), pp. 153-156

Fowler and Cleghorn, 1942. J. Fowler, F. Cleghorn. The response of splanchnic blood vessels and of the small intestine to vasoconstrictor influences in adrenal insufficiency in the cat. Am. J. Phys., 137 (1942), pp. 371-376

Fritz and Levine, 1951. I. Fritz, R. Levine. Action of adrenal cortical steroids and norepinephrine on vascular responses of stress in adrenalectomized rats. Am. J. Phys., 165 (1951), pp. 456-462

Fujita, 1977. T. Fujita. Concept of paraneurons. Arch. Histol. Jpn., 40 (Suppl) (1977), pp. 1-12 
Fujita and Kobayashi, 1979. T. Fujita, S. Kobayashi. Current views on the paraneurone concept. Trends Neurosci., 2 (1979), pp. 27-30

Gallo-Payet, 2016. N. Gallo-Payet. 60 YEARS OF POMC: adrenal and extra-adrenal functions of ACTH. J. Mol. Endocrinol., 56 (2016), pp. T135-T156

Gasser et al., 2006. P.J. Gasser, C.A. Lowry, M. Orchinik. Corticosterone-sensitive monoamine transport in the rat dorsomedial hypothalamus: potential role for organic cation transporter $\mathbf{3}$ in stress-induced modulation of monoaminergic neurotransmission. J. Neurosci., 26 (2006), pp. 8758-8766

Gasser et al., 2009. P.J. Gasser, M. Orchinik, I. Raju, C.A. Lowry. Distribution of organic cation transporter 3, a corticosterone-sensitive monoamine transporter, in the rat brain. J. Comp. Neurol., 512 (2009), pp. 529-555

Gasser et al., 2017. P.J. Gasser, M.M. Hurley, J. Chan, V.M. Pickel. Organic cation transporter 3 (OCT3) is localized to intracellular and surface membranes in select glial and neuronal cells within the basolateral amygdaloid complex of both rats and mice. Brain Struct. Funct., 222 (2017), pp. 1913-1928

Gibson, 2008. A. Gibson. The influence of endocrine hormones on the autonomic nervous system. J. Auton. Pharmacol., 1 (2008), pp. 331-358

Gilad et al., 1987. G.M. Gilad, J.M. Rabey, V.H. Gilad. Presynaptic effects of glucocorticoids on dopaminergic and cholinergic synaptosomes. Implications for rapid endocrine-neural interactions in stress. Life Sci., 40 (1987), pp. 2401-2408

Goldie, 1976. R.G. Goldie. The effects of hydrocortisone on responses to and extraneuronal uptake of (-)isoprenaline in cat and guinea-pig atria. Clin. Exp. Pharmacol. Physiol., 3 (1976), pp. 225-233

Goodman and Hajihosseini, 2015. T. Goodman, M.K. Hajihosseini. Hypothalamic tanycytes-masters and servants of metabolic, neuroendocrine, and neurogenic functions. Front. Neurosci., 9 (2015), p. 387

Gorboulev et al., 2005. V. Gorboulev, N. Shatskaya, C. Volk, H. Koepsell. Subtype-specific affinity for corticosterone of rat organic cation transporters rOCT1 and rOCT2 depends on three amino acids within the substrate binding region. Mol. Pharmacol., 67 (2005), pp. 1612-1619

Graf et al., 2013.

E.N. Graf, R.A. Wheeler, D.A. Baker, A.L. Ebben, J.E. Hill, J.R. McReynolds, M.A. Robble, O.Vranjkovic, D. S. Wheeler, J.R. Mantsch, P.J. Gasser. Corticosterone acts in the nucleus accumbens to enhance dopamine signaling and potentiate reinstatement of cocaine seeking. J. Neurosci., 33 (2013), pp. 11800-11810

Grohmann and Trendelenburg, 1984. M. Grohmann, U. Trendelenburg. The substrate specificity of uptake2 in the rat heart. Naunyn Schmiedeberg's Arch. Pharmacol., 328 (1984), pp. 164-173

Gross, 1981. P.M. Gross. Histamine H1- and H2-receptors are differentially and spatially distributed in cerebral vessels. J. Cereb. Blood Flow Metab., 1 (1981), pp. 441-446

Grundemann et al., 1997. D. Grundemann, J. Babin-Ebell, F. Martel, N. Ording, A. Schmidt, E. Schomig. Primary structure and functional expression of the apical organic cation transporter from kidney epithelial LLC-PK1 cells. J. Biol. Chem., 272 (1997), pp. 10408-10413

Grundemann et al., 1998a. D. Grundemann, S. Koster, N. Kiefer, T. Breidert, M. Engelhardt, F. Spitzenberger, N. Obermuller, E. Schomig. Transport of monoamine transmitters by the organic cation transporter type 2, OCT2. J. Biol. Chem., 273 (1998), pp. 30915-30920 
Grundemann et al., 1998b. D. Grundemann, B. Schechinger, G.A. Rappold, E. Schomig. Molecular identification of the corticosterone-sensitive extraneuronal catecholamine transporter. Nat. Neurosci., 1 (1998), pp. 349-351

Grundemann et al., 1999. D. Grundemann, G. Liebich, N. Kiefer, S. Koster, E. Schomig. Selective substrates for non-neuronal monoamine transporters. Mol. Pharmacol., 56 (1999), pp. 1-10

Grunfeld and Eloy, 1987. J.P. Grunfeld, L. Eloy. Glucocorticoids modulate vascular reactivity in the rat. Hypertension, 10 (1987), pp. 608-618

Haan et al., 2013. N. Haan, T. Goodman, A. Najdi-

Samiei, C.M. Stratford, R. Rice, A.E. El, S. Bellusci, M.K.Hajihosseini. Fgf10-expressing tanycytes add new neurons to the appetite/energy-balance regulating centers of the postnatal and adult hypothalamus. J. Neurosci., 33 (2013), pp. 6170-6180

Haas et al., 2008. H.L. Haas, O.A. Sergeeva, O. Selbach. Histamine in the central nervous system. Physiol. Rev., 88 (2008), pp. 1183-1241

Hayer-Zillgen et al., 2002. M. Hayer-Zillgen, M. Bruss, H. Bonisch. Expression and pharmacological profile of the human organic cation transporters hOCT1, hOCT2 and hOCT3. Br. J. Pharmacol., 136 (2002), pp. 829836

He et al., 2017. Q. He, Q. Wang, C. Yuan, Y. Wang. Downregulation of miR-7116-5p in microglia by MPP(+) sensitizes TNF-alpha production to induce dopaminergic neuron damage. Glia, 65 (2017), pp. 12511263

Hendley et al., 1970. E.D. Hendley, K.M. Taylor, S.H. Snyder. ${ }^{3} \mathrm{H}$-normetanephrine uptake in rat brain slices. Relationship to extraneuronal accumulation of norepinephrine. Eur. J. Pharmacol., 12 (1970), pp. 167179

Herman and Cullinan, 1997. J.P. Herman, W.E. Cullinan. Neurocircuitry of stress: central control of the hypothalamo-pituitary-adrenocortical axis. Trends Neurosci., 20 (1997), pp. 78-84

Herman et al., 1996. J.P. Herman, C.M. Prewitt, W.E. Cullinan. Neuronal circuit regulation of the hypothalamopituitary-adrenocortical stress axis. Crit. Rev. Neurobiol., 10 (1996), pp. 371-394

Herman et al., 2002a. J.P. Herman, W.E. Cullinan, D.R. Ziegler, J.G. Tasker. Role of the paraventricular nucleus microenvironment in stress integration. Eur. J. Neurosci., 16 (2002), pp. 381-385

Herman et al., 2002b. J.P. Herman, J.G. Tasker, D.R. Ziegler, W.E. Cullinan. Local circuit regulation of paraventricular nucleus stress integration: glutamate-GABA connections. Pharmacol. Biochem. Behav., 71 (2002), pp. 457-468

Herman et al., 2005. J.P. Herman, M.M. Ostrander, N.K. Mueller, H. Figueiredo. Limbic system mechanisms of stress regulation: hypothalamo-pituitary-adrenocortical axis. Prog. Neuro-Psychopharmacol. Biol. Psychiatry, 29 (2005), pp. 1201-1213

Hill and Gasser, 2013. J.E. Hill, P.J. Gasser. Organic cation transporter $\mathbf{3}$ is densely expressed in the intercalated cell groups of the amygdala: anatomical evidence for a stress hormone-sensitive dopamine clearance system. J. Chem. Neuroanat., 52 (2013), pp. 36-43

Hill et al., 2011. J.E. Hill, K. Makky, L. Shrestha, C.J. Hillard, P.J. Gasser. Natural and synthetic corticosteroids inhibit uptake 2-mediated transport in CNS neurons. Physiol. Behav., 104 (2011), pp. 306-311

Hollenberg et al., 1985.

S.M. Hollenberg, C. Weinberger, E.S. Ong, G. Cerelli, A. Oro, R. Lebo, E.B. Thompson, M.G. Rosenfeld, R. 
M. Evans. Primary structure and expression of a functional human glucocorticoid receptor cDNA. Nature, 318 (1985), pp. 635-641

Horvath et al., 2001. G. Horvath, T. Lieb, G.E. Conner, M. Salathe, A. Wanner. Steroid sensitivity of norepinephrine uptake by human bronchial arterial and rabbit aortic smooth muscle cells. Am. J. Respir. Cell Mol. Biol., 25 (2001), pp. 500-506

Horvath et al., 2003. G. Horvath, Z. Sutto, A. Torbati, G.E. Conner, M. Salathe, A. Wanner. Norepinephrine transport by the extraneuronal monoamine transporter in human bronchial arterial smooth muscle cells. Am. J. Phys. Lung Cell. Mol. Phys., 285 (2003), pp. L829-L837

Irannejad et al., 2017. R. Irannejad, V. Pessino, D. Mika, B. Huang, P.B. Wedegaertner, M. Conti, M. von Zastrow. Functional selectivity of GPCR-directed drug action through location bias. Nat. Chem. Biol., 13 (2017), pp. 799-806

Iversen, 1965. L.L. Iversen. The uptake of adrenaline by the rat isolated heart. Br. J. Pharmacol., 24 (1965), pp. 387-394

Iversen and Salt, 1970. L.L. Iversen, P.J. Salt. Inhibition of catecholamine Uptake-2 by steroids in the isolated rat heart. Br. J. Pharmacol., 40 (1970), pp. 528-530

Jutel et al., 2006. M. Jutel, K. Blaser, C.A. Akdis. The role of histamine in regulation of immune responses. Chem. Immunol. Allergy, 91 (2006), pp. 174-187

Kalivas and Duffy, 1995. P.W. Kalivas, P. Duffy. Selective activation of dopamine transmission in the shell of the nucleus accumbens by stress. Brain Res., 675 (1995), pp. 325-328

Kalsner, 1969. S. Kalsner. Steroid potentiation of responses to sympathomimetic amines in aortic strips. Br. J. Pharmacol., 36 (1969), pp. 582-593

Kalsner, 1974. S. Kalsner. Sensitization of noradrenaline responses by inhibitors of extraneuronal uptake in a coronary artery preparation. Br. J. Pharmacol., 51 (1974), pp. 453-455

Kekuda et al., 1998. R. Kekuda, P.D. Prasad, X. Wu, H. Wang, Y.J. Fei, F.H. Leibach, V. Ganapathy. Cloning and functional characterization of a potential-sensitive, polyspecific organic cation transporter (OCT3) most abundantly expressed in placenta. J. Biol. Chem., 273 (1998), pp. 15971-15979

Koepsell et al., 2007. H. Koepsell, K. Lips, C. Volk. Polyspecific organic cation transporters: structure, function, physiological roles, and biopharmaceutical implications. Pharm. Res., 24 (2007), pp. 1227-1251

LeComte et al., 1959. J. LeComte, J. Grevisse, M.L. Beaumariage. Hydrocortisone potentiation of the motor effects of adrenalin. Arch. Int. Pharmacodyn. Ther., 119 (1959), pp. 133-141

Lepri and Cristiani, 1964. G. Lepri, R. Cristiani. The ability of certain adrenocortical hormones to potentiate the vasoconstrictor action of nor-adrenaline on the conjunctival vessels in the rabbits and in man. $\mathrm{Br}$. J. Ophthalmol., 48 (1964), pp. 205-208

Li et al., 2013. R.W. Li, C. Yang, Y.W. Kwan, S.W. Chan, S.M. Lee, G.P. Leung. Involvement of organic cation transporter-3 and plasma membrane monoamine transporter in serotonin uptake in human brain vascular smooth muscle cells. Front. Pharmacol., 4 (2013), p. 14

Lightman and Iversen, 1969. S.L. Lightman, L.L. Iversen. The role of uptake ${ }_{2}$ in the extraneuronal metabolism of catecholamines in the isolated rat heart. Br. J. Pharmacol., 37 (1969), pp. 638-649

Lowry et al., 1996. C.A. Lowry, K.J. Renner, F.L. Moore. Catecholamines and indoleamines in the central nervous system of a urodele amphibian: a microdissection study with emphasis on the distribution of epinephrine. Brain Behav. Evol., 48 (1996), pp. 70-93 
Lowry et al., 2001. C.A. Lowry, K.A. Burke, K.J. Renner, F.L. Moore, M. Orchinik. Rapid changes in monoamine levels following administration of corticotropin-releasing factor or corticosterone are localized in the dorsomedial hypothalamus. Horm. Behav., 39 (2001), pp. 195-205

Lowry et al., 2003. C.A. Lowry, A. Plant, N. Shanks, C.D. Ingram, S.L. Lightman. Anatomical and functional evidence for a stress-responsive, monoamine-accumulating area in the dorsomedial hypothalamus of adult rat brain. Horm. Behav., 43 (2003), pp. 254-262

Marowsky et al., 2005. A. Marowsky, Y. Yanagawa, K. Obata, K.E. Vogt. A specialized subclass of interneurons mediates dopaminergic facilitation of amygdala function. Neuron, 48 (2005), pp. 1025-1037

Martel et al., 1999. F. Martel, L. Ribeiro, C. Calhau, I. Azevedo. Comparison between uptake ${ }_{2}$ and rOCT1: effects of catecholamines, metanephrines and corticosterone. Naunyn Schmiedeberg's Arch.

Pharmacol., 359 (1999), pp. 303-309

Martel et al., 2000. F. Martel, C. Calhau, I. Azevedo. Characterization of the transport of the organic cation [ $\left.{ }^{3} \mathrm{H}\right] \mathrm{MPP}+$ in human intestinal epithelial (Caco-2) cells. Naunyn Schmiedeberg's Arch. Pharmacol., 361 (2000), pp. 505-513

McReynolds et al., 2010. J.R. McReynolds, K. Donowho, A. Abdi, J.L. McGaugh, B. Roozendaal, C.K. McIntyre. Memory-enhancing corticosterone treatment increases amygdala norepinephrine and Arc protein expression in hippocampal synaptic fractions. Neurobiol. Learn. Mem., 93 (2010), pp. 312-321

McReynolds et al., 2017.

J.R. McReynolds, A. Taylor, O. Vranjkovic, T. Ambrosius, O. Derricks, B. Nino, B.Kurtoglu, R.A. Wheeler, D.A. Baker, P.J. Gasser, J.R. Mantsch. Corticosterone potentiation of cocaine-induced reinstatement of conditioned place preference in mice is mediated by blockade of the organic cation transporter 3 . Neuropsychopharmacology, 42 (2017), pp. 757-765

Mittleman et al., 1992. G. Mittleman, C.D. Blaha, A.G. Phillips. Pituitary-adrenal and dopaminergic modulation of schedule-induced polydipsia: behavioral and neurochemical evidence. Behav.

Neurosci., 106 (1992), pp. 408-420

Moore and Evans, 1999. F.L. Moore, S.J. Evans. Steroid hormones use non-genomic mechanisms to control brain functions and behaviors: a review of evidence. Brain Behav. Evol., 54 (1999), pp. 41-50

Moore and Miller, 1984. F.L. Moore, L.J. Miller. Stress-induced inhibition of sexual behavior: corticosterone inhibits courtship behaviors of a male amphibian (Taricha granulosa). Horm. Behav., 18 (1984), pp. $400-410$

Moore and Orchinik, 1994. F.L. Moore, M. Orchinik. Membrane receptors for corticosterone: a mechanism for rapid behavioral responses in an amphibian. Horm. Behav., 28 (1994), pp. 512-519

Moore et al., 1995. F.L. Moore, M. Orchinik, C. Lowry. Functional studies of corticosterone receptors in neuronal membranes. Receptor, 5 (1995), pp. 21-28

Muller and Da, 1977. J. Muller, L.C. Da. Ultracytochemical demonstration of monoamine oxidase activity in nervous and non-nervous tissue of the rat. J. Histochem. Cytochem., 25 (1977), pp. 337-348

Myohanen and Mannisto, 2010. T.T. Myohanen, P.T. Mannisto. Distribution and functions of catechol-Omethyltransferase proteins: do recent findings change the picture? Int. Rev. Neurobiol., 95 (2010), pp. 29-47

Nakamura et al., 2017. Y. Nakamura, K. Ishimaru, S. Shibata, A. Nakao. Regulation of plasma histamine levels by the mast cell clock and its modulation by stress. Sci. Rep., 7 (2017), Article 39934 
Orchinik et al., 1991. M. Orchinik, T.F. Murray, F.L. Moore. A corticosteroid receptor in neuronal membranes. Science, 252 (1991), pp. 1848-1851

Orchinik et al., 1997. M. Orchinik, N. Hastings, D. Witt, B.S. McEwen. High affinity binding of corticosterone to mammalian neuronal membranes: possible role of corticosteroid binding globulin. J. Steroid Biochem. Mol. Biol., 60 (1997), pp. 229-236

Orchinik et al., 2009. M. Orchinik, P.J. Gasser, C.A. Lowry. Acute corticosteroid actions in the brain: cellular mechanisms and behavioral consequences. D. Pfaff, A. Etgen (Eds.), Molecular Mechanisms of Hormone Actions on Behavior, Academic Press, San Diego, CA (2009)

Pare et al., 2004. D. Pare, G.J. Quirk, J.E. LeDoux. New vistas on amygdala networks in conditioned fear. J. Neurophysiol., 92 (2004), pp. 1-9

Piazza et al., 1996. P.V. Piazza, F. Rouge-Pont, V. Deroche, S. Maccari, H. Simon, M. Le Moal. Glucocorticoids have state-dependent stimulant effects on the mesencephalic dopaminergic transmission. Proc. Natl. Acad. Sci. U. S. A., 93 (1996), pp. 8716-8720

Rahman et al., 2008. Z. Rahman, R.H. Ring, K. Young, B. Platt, Q. Lin, L.E. Schechter, S. RosenzweigLipson, C.E. Beyer. Inhibition of uptake 2 (or extraneuronal monoamine transporter) by normetanephrine potentiates the neurochemical effects of venlafaxine. Brain Res., 1203 (2008), pp. 68-78

Ramey et al., 1951. E. Ramey, M. Goldstein, R. Levine. Action of norepinephrine and adrenal cortical steroids on blood pressure and work performance of adrenalectomized dogs. Am. J. Phys., 105 (1951), pp. 450-457

Reis, 1960. D.J. Reis. Potentiation of the vasoconstrictor action of topical norepinephrine on the human bulbar conjunctival vessels after topical application of certain adrenocortical hormones. J. Clin. Endocrinol. Metab., 20 (1960), pp. 446-456

Russ et al., 1992. H. Russ, M. Gliese, J. Sonna, E. Schomig. The extraneuronal transport mechanism for noradrenaline (uptake ${ }_{2}$ ) avidly transports 1-methyl-4-phenylpyridinium (MPP+). Naunyn Schmiedeberg's Arch. Pharmacol., 346 (1992), pp. 158-165

Sala et al., 2008. F. Sala, A. Nistri, M. Criado. Nicotinic acetylcholine receptors of adrenal chromaffin cells. Acta Physiol (Oxford), 192 (2008), pp. 203-212

Sapolsky and Share, 1994. R.M. Sapolsky, L.J. Share. Rank-related differences in cardiovascular function among wild baboons: role of sensitivity to glucocorticoids. Am. J. Primatol., 32 (1994), pp. 261-275

Sapolsky et al., 2000. R.M. Sapolsky, L.M. Romero, A.U. Munck. How do glucocorticoids influence stress responses? Integrating permissive, suppressive, stimulatory, and preparative actions. Endocr. Rev., 21 (2000), pp. 55-89

Schayer, 1963. R.W. Schayer. Histamine and autonomous responses of the microcirculation; relationship to glucocorticoid action. Ann. N. Y. Acad. Sci., 116 (1963), pp. 891-898

Schneider et al., 2005.

E. Schneider, F. Machavoine, J.M. Pleau, A.F. Bertron, R.L. Thurmond, H. Ohtsu, T.Watanabe, A.H. Schin kel, M. Dy. Organic cation transporter 3 modulates murine basophil functions by controlling intracellular histamine levels. J. Exp. Med., 202 (2005), pp. 387-393

Schomig et al., 1976. A. Schomig, B. Luth, R. Dietz, F. Gross. Changes in vascular smooth muscle sensitivity to vasoconstrictor agents induced by corticosteroids, adrenalectomy and differing salt intake in rats. Clin. Sci. Mol. Med. Suppl., 3 (1976), pp. 61s-63s 
Schomig et al., 1998. E. Schomig, F. Spitzenberger, M. Engelhardt, F. Martel, N. Ording, D. Grundemann. Molecular cloning and characterization of two novel transport proteins from rat kidney. FEBS Lett., 425 (1998), pp. 79-86

Schomig et al., 2006. E. Schomig, A. Lazar, D. Grundemann. Extraneuronal monoamine transporter and organic cation transporters 1 and 2: a review of transport efficiency. Handb. Exp. Pharmacol. (2006), pp. 151180

Shang et al., 2003. T. Shang, A.V. Uihlein, J. Van Asten, B. Kalyanaraman, C.J. Hillard. 1-Methyl-4phenylpyridinium accumulates in cerebellar granule neurons via organic cation transporter 3 . J. Neurochem., 85 (2003), pp. 358-367

Shaskan and Snyder, 1970. E.G. Shaskan, S.H. Snyder. Kinetics of serotonin accumulation into slices from rat brain: relationship to catecholamine uptake. J. Pharmacol. Exp. Ther., 175 (1970), pp. 404-418

Sladek Jr and Sladek, 1978. J.R. Sladek Jr., C.D. Sladek. Localization of serotonin within tanycytes of the rat median eminence. Cell Tissue Res., 186 (1978), pp. 465-474

Soares-Da-Silva and Pinto, 1996. P. Soares-Da-Silva, D.O.P. Pinto. Antagonistic actions of renal dopamine and 5hydroxytryptamine: effects of amine precursors on the cell inward transfer and decarboxylation. $\mathrm{Br}$. J. Pharmacol., 117 (1996), pp. 1187-1192

Stamper et al., 2015.

C.E. Stamper, P.A. Hennessey, M.W. Hale, J.L. Lukkes, N.C. Donner, K.R. Lowe, E.D. Paul, R.L. Spencer, K. J. Renner, M. Orchinik, C.A. Lowry. Role of the dorsomedial hypothalamus in glucocorticoid-mediated feedback inhibition of the hypothalamic-pituitary-adrenal axis. Stress, 18 (2015), pp. 76-87

Stamper et al., 2017. C.E. Stamper, J.E. Hassell Jr., A.J. Kapitz, K.J. Renner, M. Orchinik, C.A. Lowry. Activation of 5- $\mathrm{HT}_{1 \mathrm{~A}}$ receptors in the rat dorsomedial hypothalamus inhibits stress-induced activation of the hypothalamic-pituitary-adrenal axis. Stress, 20 (2017), pp. 223-230

Takeda et al., 2002. H. Takeda, M. Inazu, T. Matsumiya. Astroglial dopamine transport is mediated by norepinephrine transporter. Naunyn Schmiedeberg's Arch. Pharmacol., 366 (2002), pp. 620-623

Tanz, 1960. R.D. Tanz. Studies on the action of cortisone acetate on isolated cardiac tissue. J. Pharmacol. Exp. Ther., 128 (1960), pp. 168-175

Towle and Sze, 1983. A.C. Towle, P.Y. Sze. Steroid binding to synaptic plasma membrane: differential binding of glucocorticoids and gonadal steroids. J. Steroid Biochem., 18 (1983), pp. 135-143

Turner et al., 2012. A.I. Turner, C.L. Keating, A.J. Tilbrook. Sex differences and the role of sex steroids in sympatho-adrenal medullary system and hypothalamo-pituitary adrenal axis responses to stress, sex steroids. S.M. Kahn (Ed.), Sex Steroids, InTech, Rijeka, Croatia (2012), pp. 115-136

Ulmanen et al., 1997.

I. Ulmanen, J. Peranen, J. Tenhunen, C. Tilgmann, T. Karhunen, P. Panula, L. Bernasconi, J.P. Aubry, K. Lu ndstrom. Expression and intracellular localization of catechol O-methyltransferase in transfected mammalian cells. Eur. J. Biochem., 243 (1997), pp. 452-459

Vaniotis et al., 2013.

G. Vaniotis, I. Glazkova, C. Merlen, C. Smith, L.R. Villeneuve, D. Chatenet, M. Therien, A.Fournier, A. Tad evosyan, P. Trieu, S. Nattel, T.E. Hebert, B.G. Allen. Regulation of cardiac nitric oxide signaling by nuclear beta-adrenergic and endothelin receptors. J. Mol. Cell. Cardiol., 62 (2013), pp. 58-68

Vialou et al., 2004. V. Vialou, A. Amphoux, R. Zwart, B. Giros, S. Gautron. Organic cation transporter 3 (SIc22a3) is implicated in salt-intake regulation. J. Neurosci., 24 (2004), pp. 2846-2851 
Vieira-Coelho and Soares-Da-Silva, 1997. M.A. Vieira-Coelho, P. Soares-Da-Silva. Apical and basal uptake of Ldopa and L-5-HTP and their corresponding amines, dopamine and 5-HT, in OK cells. Am. J. Physiol. Ren. Physiol., 272 (1997), pp. F632-F639

Vieira-Coelho and Soares-Da-Silva, 1998. M.A. Vieira-Coelho, P. Soares-Da-Silva. Uptake and intracellular fate of L-DOPA in a human intestinal epithelial cell line: Caco-2. Am. J. Phys., 275 (1998), pp. C104-C112

Volk et al., 2003. C. Volk, V. Gorboulev, T. Budiman, G. Nagel, H. Koepsell. Different affinities of inhibitors to the outwardly and inwardly directed substrate binding site of organic cation transporter 2 . Mol. Pharmacol., 64 (2003), pp. 1037-1047

Volk et al., 2009. C. Volk, V. Gorboulev, A. Kotzsch, T.D. Muller, H. Koepsell. Five amino acids in the innermost cavity of the substrate binding cleft of organic cation transporter 1 interact with extracellular and intracellular corticosterone. Mol. Pharmacol., 76 (2009), pp. 275-289

Wheeler et al., 2017.

D.S. Wheeler, A.L. Ebben, B. Kurtoglu, M.E. Lovell, A.T. Bohn, I.A. Jasek, D.A. Baker, J.R.Mantsch, P.J. Ga sser, R.A. Wheeler. Corticosterone regulates both naturally occurring and cocaine-induced dopamine signaling by selectively decreasing dopamine uptake. Eur. J. Neurosci., 46 (2017), pp. 2638-2646

Wu and O'Connell, 2015. S.C. Wu, T.D. O'Connell. Nuclear compartmentalization of alpha1-adrenergic receptor signaling in adult cardiac myocytes. J. Cardiovasc. Pharmacol., 65 (2015), pp. 91-100

Wu et al., 1998. X. Wu, R. Kekuda, W. Huang, Y.J. Fei, F.H. Leibach, J. Chen, S.J. Conway, V. Ganapathy. Identity of the organic cation transporter ОСТ3 as the extraneuronal monoamine transporter (uptake ( $_{2}$ ) and evidence for the expression of the transporter in the brain. J. Biol. Chem., 273 (1998), pp. 32776 32786

Wu et al., 2014. S.C. Wu, E.F. Dahl, C.D. Wright, A.L. Cypher, C.L. Healy, T.D. O'Connell. Nuclear localization of a1A-adrenergic receptors is required for signaling in cardiac myocytes: an "inside-out" a1-AR signaling pathway. J. Am. Heart Assoc., 3 (2014), Article e000145

Yoshikawa et al., 2013.

T. Yoshikawa, F. Naganuma, T. lida, T. Nakamura, R. Harada, A.S. Mohsen, A. Kasajima, H. Sasano, K. Ya nai. Molecular mechanism of histamine clearance by primary human astrocytes. Glia, 61 (2013), pp. 905-916

Zhang et al., 1998. L. Zhang, M.E. Schaner, K.M. Giacomini. Functional characterization of an organic cation transporter (hOCT1) in a transiently transfected human cell line (HeLa). J. Pharmacol. Exp. Ther., 286 (1998), pp. 354-361

Zwart et al., 2001. R. Zwart, S. Verhaagh, M. Buitelaar, C. Popp-Snijders, D.P. Barlow. Impaired activity of the extraneuronal monoamine transporter system known as uptake-2 in Orct3/SIc22a3-deficient mice. Mol. Cell. Biol., 21 (2001), pp. 4188-4196 